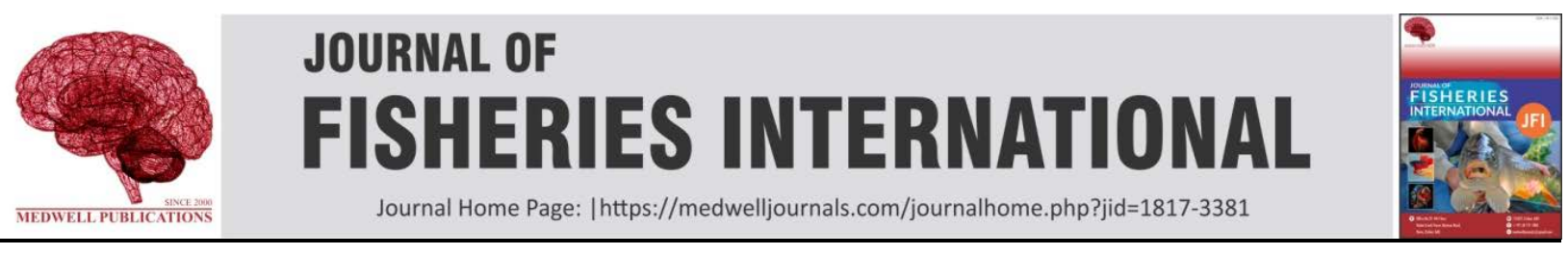

\title{
Compliance with Fishing Regulations in Lakes Geriyo and Ribadu, North Eastern Nigeria
}

\author{
${ }^{1}$ B.P. Kwaji, ${ }^{2}$ O.A. Sogbesan and ${ }^{3}$ K.J. Peter \\ ${ }^{1,2}$ Department of Fisheries, Modibbo Adama University of Technology, Yola, Nigeria \\ ${ }^{3}$ Department of Fisheries and Aquaculture, Adamawa State University, Mubi, Nigeria
}

Key words: Compliance, fishers, fishing regulations, lakes, disastrous

Page No.: $19-22$

Volume: 14 Issue 03, 2019

ISSN: $1817-3381$

Journal of Fisheries International

Copy Right: Medwell Publications

\begin{abstract}
Artisanal fishery has been of immense importance to human existence worldwide. Fishing regulations have not been effective due to non-compliance. This is disastrous to the fisheries as it could lead to collapse and fishery closure. The study was carried out to ascertain the fisher's compliance with fishing regulations in lakes Geriyo and Ribadu, Nigeria. Data were collected through surveys and enumerator interview from forty-two respondents; twenty-one in each lake. Data collected were analysed using descriptive statistics and t-test with Microsoft Excel 2007. Result shows that ban on explosives was the most complied regulation in lake Geriyo (100\%) while the most violated was mesh size regulation (47\%). In lake Ribadu, ban on explosives was also the most complied regulation (100\%) while the least was also mesh size regulation (33.33\%). The respondent's compliance in the lakes was significant $(\mathrm{p}<0.05)$. Economic reason was the primary and leading motive for non-compliance with regulations in the study areas. Government should tackle fisher's low economic status, invest in their education, enlighten them on the need for conservation, step-up regulation enforcement and integrate the fishers as key stakeholders in any fisheries management plan.
\end{abstract}

\section{INTRODUCTION}

The importance of small-scale capture fisheries has been recognised internationally because of its relevant contribution in food and nutritional security, poverty alleviation, economic growth, job and employment creation (Alayon, 2011). Natural resources are often a Common-Pool Resource (CPR) type which implies problems with overexploitation that sometimes are hard to manage, even in well developed countries (Eggert and Lokina, 2008). Fishing regulations have not been effective due to non-compliance with the regulations by fishers (Koranteng, 1996). This is disastrous to the fisheries. It could lead to overexploitation and overcapitalization and consequently run into extinction and deepen poverty as well as unemployment in fishing communities (Abusin and Hassan, 2012). Violating fishing regulations is a criminal activity that leads to depletion of fish stocks levels across the world (Akpalu, 2009). This is more popular in developing countries where monitoring and enforcement of fishery regulations are far from being complete (Akpalu, 2009; FAO., 2001). African tropical lakes are believed to be fully exploited and even over-fished in some parts. This presents a big threat to the capacity of these fishery ecosystems to continue providing for the livelihood of many communities which are locally highly dependent on their harvest (Millennium Ecosystem Assessment, 2005).

The practice of illegal fishing, particularly the use of small mesh size in an already over-fished stock will lead to stock collapse and fishery closure. This calls for urgent action to reduce non-compliance with fishery regulations, especially on the use of small mesh size because it removes small fish, hence, limiting the opportunity for reproduction (Clark, 1990). Although, illegal fishing is prevalent, a review of literature reveals that few studies have sought to understand the motives behind it (Hepworth, 2011). Understanding the factors that motivate fisher's decision to infringe on regulations and how they interact with contextual conditions may improve future compliance and rules efficiency (Alayon, 2011). Poor people are frequently compelled to exploit their surroundings for short term survival and are the group of people who must regularly deal with natural resources degradation. Enforcement issues can arise due to many factors such as lack of surveillance, remoteness of site, 
failure to assign enforcement responsibility, lack of funds for policy or lack of public support which lead to socially accepted poaching (Jones, 2002). According to Abusin and Hassan (2012), unless there is close understanding of violation behavior and reasons for noncompliance with regulations, non-compliance is expected to increase to the extent that the stocks may collapse. Achieving compliance with fishery regulations is therefore becoming an issue of serious concern to managers and policy makers worldwide given the high cost of enforcement and low probability of detection (Abusin and Hassan, 2012).

To design a more effective management plan, more research is needed to gain better understanding of fisher's non-compliance motives and behavior (Abusin and Hassan, 2012). Illegal fishing is an uneasy to observe problem, information on which cannot be obtained from governments and fisheries departments but mostly based on surveys and interviews (King and Sutinen, 2010). Understanding fisher's violation behavior is crucial for improving fisheries enforcement or regulatory system (John, 2006). In view of that, the study was carried out to investigate the extent of fisher's compliance with fishing regulations and likely reasons that are responsible for non-compliance in lakes Geriyo and Ribadu, Adamawa state, Nigeria. The results will help the fisheries administration to evaluate and improve existing strategies and plans in the fisheries and also serve as useful reference material for fisheries managers, policy makers and academicians.

\section{MATERIALS AND METHODS}

The study was carried out in lakes Geriyo, situated in latitude $9.30^{\circ} \mathrm{N}$ and longitude $12.40^{\circ} \mathrm{E}$ and Ribadu, situated in latitude $9.31^{\circ} \mathrm{N}$ and longitude $13.12^{\circ} \mathrm{E}$ both located in North-Eastern Nigeria. Data were collected through surveys, enumerator interview and group discussions with randomly selected fishers and other stakeholders in the lakes in June, 2015. Forty-two fishermen; twenty-one in each Lake were interviewed for the study. Data generated were compiled, computed and analyzed using simple descriptive statistics and t-test with Microsoft Excel 2007.

\section{RESULTS AND DISCUSSION}

Table 1 shows the respondent's compliance with fishing regulations in the study areas. Ban on use of explosives was the most complied regulation (100\%) in lake Geriyo followed by fishing effort control (95.24\%), closed season (95.24\%), ban on fish poison (90.48\%), declaration of caches (85.71\%), ban on fish fence (80.95\%) and closed area (80.95\%). Only few of the respondents adhered with regulation on mesh size (47.62\%). In lake Ribadu, ban on explosives was also the most practiced regulation (100\%) followed by ban on fish poison (85.71\%), closed area (76.19\%), ban on fish fence (71.43\%), closed season (66.67\%) and fishing effort control (52.38\%). Only $42.86 \%$ of the respondents complied with declaration of catches and $33.33 \%$ with mesh size regulation. This result which compares favorably with the report by Nwabeze and Erie (2013), Akpalu (2009) and Abusin and Hassan (2012) shows that the respondents in lake Geriyo complied with fishing regulations more than those in lake Ribadu and the compliance was significant $(p<0.05)$. This could be because of inadequate monitoring, control, surveillance in and remoteness of the lake Ribadu as they are known to affect enforcement of regulations (John, 2006). In both lakes, mesh size regulation was the most violated regulation. This agrees with the findings by Clark (1990) and Akpalu (2009). This could be as a result of the fisher's quest to increase their catches and thus employed the use of gears with undersize mesh size as well as ineffective enforcement of regulations. This practice could lead to stock collapse and fishery closure as it removes small size fish before they attain maturity and hence, limiting the opportunity for reproduction (Clark, 1990). Mesh size regulation, among others has not been very effective due to noncompliance. When asked, the fishers said legal mesh size cannot catch targeted species in quantity they want (Akpalu, 2009).

The respondent's reasons for non-compliance with fishing regulations as shown in Fig. 1 and 2 indicate that $85.71 \%$ of the respondents in lake Geriyo violated fishing regulations for economic reasons followed by ignorance (47.62\%), deliberate violation (42.86\%) because of weak penalties (38.09\%). Only 33.33\% of the respondents violated regulations because of inadequate Monitoring, Control and Surveillance (MCS). In lake Ribadu, 90.48\% of the respondents did not comply with regulations for economic reasons, $76.19 \%$ violated because of inadequate MCS, 52.38\% because of ignorance, $52.38 \%$ because of weak penalties of violation and $47.62 \%$ violated the regulations deliberately. In both lakes, most of the respondents violated fishing regulations for economic reasons. This confirms the report by Hepworth who stressed that the primary reason for noncompliance with fishing regulations was economic with lack of education and awareness exacerbating the problem. Non-compliance because of ignorance agrees with the report by John (2006) who stressed that some fishers violate regulations as a result of 
J. Fish. Int., 14 (3): 19-22, 2019

Table 1: Respondent's compliance with fishing regulations in the study areas

\begin{tabular}{|c|c|c|c|c|}
\hline \multirow[b]{2}{*}{ Category of regulation } & \multicolumn{2}{|l|}{ Lake Geriyo } & \multicolumn{2}{|l|}{ Lake Ribadu } \\
\hline & Frequency* & Percentage & Frequency* & Percentage \\
\hline Ban on explosives & 21 & 100 & 21 & 100 \\
\hline Ban on fish poison & 19 & 90.48 & 18 & 85.71 \\
\hline Ban on fish fence & 17 & 80.95 & 15 & 71.43 \\
\hline Mesh size regulation & 10 & 47.62 & 7 & 33.33 \\
\hline Declaration of catch & 18 & 85.71 & 9 & 42.86 \\
\hline Fishing effort control & 20 & 95.24 & 11 & 52.38 \\
\hline Closed season & 20 & 95.24 & 14 & 66.67 \\
\hline Closed area & 17 & 80.95 & 16 & 76.19 \\
\hline
\end{tabular}

*Multiple responses

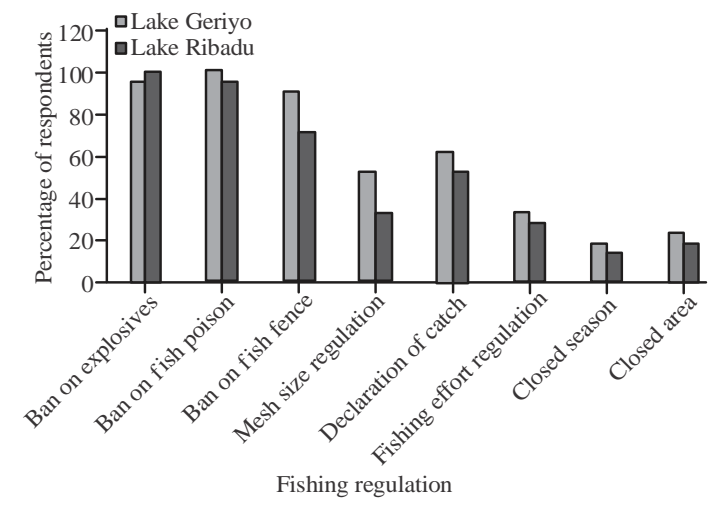

Fig. 1: Proportion of respondents in agreement with fishing regulations in the study areas

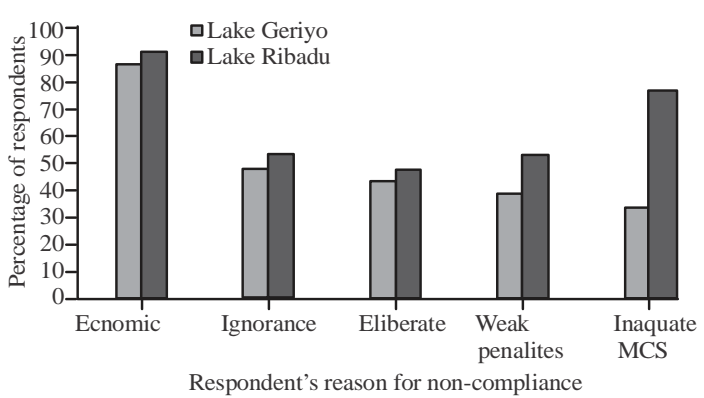

Fig. 2: Respondent's reasons for non-compliance with fishing regulations in the study areas; MCS: Monitoring, Control and Surveillance

unawareness on the regulations. Some of the respondents in lake Ribadu expressed their desperation for money to improve their standard of living. According to King and Sutinen (2010), regulatory compliance in fisheries depends to a great extent on economic variables. The proportion of the respondents who violated regulations because of inadequate MCS reveals lack of enforcement by appropriate authorities in the lakes. Similar situation was reported by Nwabeze and Erie (2013) in lake Jebba, Nigeria that poor implementation of sanctions by authorities increased non-compliance with fishing regulations. According to Eggert and Lokina (2008), illegal fishing will occur if enforcement effort is not so high as to remove the incentive to do so and if the effective violation is not too great, nor its cost too low. When violation is neither too cheap nor too effective, the interaction between violation and enforcement is regular and the more enforcement, the less violation.

There are several other reasons that could influence fisher's non-compliance behavior. These include potential gain from illegal fishing, certainty of sanctions, individual moral development, social environmental influence, low level of education, lack of viable alternative livelihoods (Alayon, 2011), corruption by enforcement agencies, lack of respect for law (Wood, 2004). Others are poor communication between fishers and government (Gray and Hatchard, 2003) which could lead to misunderstanding and thus inaction and misinterpretation. Many fishing communities are heavily reliant on fisheries resources with few alternative livelihoods available and so fishers cannot meet their daily needs by legal fishing. According to Thomas and Baberton fishers will observe fishing regulations unless under economic pressure to increase their catches.

As shown in Fig. 1 in lake Geriyo, ban on fish poison received the highest support (100\%) among the respondents, followed by ban on explosives (95.24\%), ban on fish fence (90.48\%), declaration of catches (61.90\%), mesh size regulation (52.38\%). Fishing effort control (33.33\%), closed area (23.81\%). Closed season had the least support from the respondents (19.05\%). In lake Ribadu, ban on explosives had the highest support (100\%) followed by ban on fish poison (95.24\%), ban on fish fence (71.43\%), declaration of catches (52.38\%) mesh size regulation (33.33\%), fishing effort control (28.57\%) and closed area (19.05\%). Closed season received the least support (14.28\%) from the respondents. The result shows that closed season received the least support from the respondents in both lakes. This could be because of the fisher's reliance on the lake's resources for livelihoods.

\section{CONCLUSION}

Fish and fisheries products have been of immense importance to human existence. The need to ensure sustainability of the benefits of the resources cannot be overstated. The study revealed low compliance with some and low support for some important fishing regulations by respondents in lake Ribadu than those in lake Geriyo with 
ban on explosives and mesh size regulation being the most complied and violated regulations in both lakes, respectively. Result of the respondent's motives for non-compliance with regulations shows that economic reasons was the primary and leading motive for violating fishing regulations in the study areas. There is need to take into account not only biological but institutional, social, economical and political objectives in any management plan. From economic point of view, the fisher's non-compliance behavior should be tackled by creating viable alternative livelihoods for them in order to reduce their reliance on the resources. The status of the fishers as key stakeholders in the fisheries sector should be recognized and therefore, integrate them in any management plan. Government should invest heavily in fisher's education and also enlighten them on the importance and need for conservation of the resources. This will enable them appreciate regulations and conservation. There should be high enforcement of regulations alongside adequate MCS in the lakes. penalties for violation should be severe enough to render gain not worth effort. This can be achieved by establishing fisheries Inspectorate to conduct regular surveillance in the lakes.

\section{REFERENCES}

Abusin, S. and R. Hassan, 2012. Non-compliance with fishery regulation by fisher typology in Sudan. Ph.D. Thesis, Center for Environmental Economics and Policy in Africa (CEEPA), University of Pretoria, Pretoria, South Africa.

Akpalu, W., 2009. Compliance to mesh size regulation in artisanal marine fishery in Ghana. Ph.D. Thesis, Department of Economics, University of Gothenburg, Sweden.

Alayon, L.M., 2011. Regulatory compliance in small-scale fisheries in old providence Island, Colombia. M.Sc. Thesis, University of Massachusetts Amherst, Amherst, Massachusetts, USA.

Clark, C.W., 1990. Mathematical Bioeconomics: The Optimal Management of Renewable Resources. Wiley, New York.
Eggert, H. and R.B. Lokina, 2008. Regulatory compliance in lake victory. Environmental Development Paper Series, Environmental Development, USA.

FAO., 2001. Reports and papers presented at the expert consultation on Illegal, unreported and unregulated fishing. Food and Agriculture Organization Sydney, Australia.

Gray, T. and J. Hatchard, 2003. The 2002 reform of the common fisheries policy's system of governance-rhetoric or reality?. Mar. Policy, 27: 545-554.

Hepworth, L., 2011. Breaking or following the fishing rules and regulations: Motivations, benefits and incentives for Kia Islanders, Fiji. M.Sc. Thesis, University of Brighton, Brighton, England.

John, A.A., 2006. Status of fisheries regulations in Nigeria. B.Sc. Thesis, Department of Aquaculture and Fisheries Management, Federal University of Agriculture, Abeokuta, Nigeria.

Jones, P.J., 2002. Marine protected area strategies: Issues, divergences and the search for middle ground. Rev. Fish Bio. Fisheries, 11: 197-216.

King, D.M. and J.G. Sutinen, 2010. Rational non-compliance and liquidation of north-east ground fish resources. Mar. Policy, 34: 7-21.

Koranteng, K.A., 1996. The marine artisanal fishery in Ghana: Recent developments and implications for resource evaluation. Proceedings of the World Fisheries Congress on Fisheries Resource Utilization and Policy Theme, Vol. 2, May 3-8, 1996, Athens, Greece, pp: 498-509.

Millennium Ecosystem Assessment, 2005. Ecosystem and Human Well-Being: Wetlands and Water Synthesis. World Resources Institute, Washington, DC., USA.

Nwabeze, G.O. and A.P. Erie, 2013. Artisanal fisher's use of sustainable fisheries management practices in the Jebba Lake Basin, Nigeria. J. Agric. Extension, 17: $123-134$.

Wood, L., 2004. Motives of poaching in MPAs in Seychelles West Indian Ocean. J. Mar. Sci., 3: 199-208. 